\title{
The Effect of Current Density on the Properties of Porous Silicon Gas Sensor for Ethanol and Methanol Vapour Detection
}

\author{
Muna H. Kareem*, Adi M., Haitham T. Hussein \\ Department of Applied Science, University of Technology - Iraq
}

\section{Article information}

Article history:

Received: June, 16, 2021

Accepted: October, 10, 2021

Available online: December, 04, 2021

Keywords:

Porous silicon (PS),

Ethanol gas sensor,

Methanol gas sensor,

Photo-electrochemical etching

*Corresponding Author:

Muna Hussein Kareem

as.18.82@grad.uotechnoiogy.edu.iqm

\begin{abstract}
In this paper, Gas sensors for ethanol and methanol were created utilizing porous silicon (PSi).n-type silicon was employed for all PSi samples, photo-electrochemical etching technique (PECE) was used to prepare porous surface. The intensity of the three etchings current densities was 12,24 and $30 \mathrm{~mA} / \mathrm{cm}^{2}$, with $40 \%$ hydrofluoric acid concentration (HF) and a time of etching 10 minutes. Porous silicon (100) has been strictly studied by the structure and formation of surface bonding of the PSi layer; the structural properties, morphological characteristics, pore diameter, and roughness were described using Xray diffraction (XRD), atomic force microscopy (AFM) and scanning electron microscopy (SEM). All PSi samples were applied as a sensor for ethanol and methanol at room temperature. The results showed that the best sensitivity of PSi was to ethanol gas compared to methane under the same used conditions at etching current density $30 \mathrm{~mA} / \mathrm{cm} 2$, reaching about 1.809 at a concentration of $500 \mathrm{ppm}$. From these results, the PSi layers act as high-quality, low-cost gas sensors. It can be used as a replacement for expensive material that is used as gas sensors, which operate at low temperatures, including room temperature. The interest in this material is due to study the effect of extremely high surface to volume ratio (increasing surface area), and easy manufactured and compatibility with modern silicon microelectronics manufacturing technologies.
\end{abstract}

DOI: 10.53293/jasn.2021.3834.1048, Department of Applied Sciences, University of Technology

This is an open access article under the CC BY 4.0 License.

\section{Introduction}

Porous silicon (PSi) has been extensively researched since the discovery of its effective photoluminescence in the visible light range. By combining the PSi structure's large surface area and unique optical and electrical properties with a semiconductor nanostructure, it is possible to produce low-cost light-emitting materials, which is economically useful and important nowadays, and it serves as a good substrate for many fabrication techniques [1]. PSi may be considered as a silicon crystal with a network of voids in it. Because of the nanosized "gaps" in the silicon bulk, a sponge-like structure of pores and channels is formed, surrounded by a skeleton of crystal-line silicon nanowires. [2]. Where the PSi surface seems to be a fragile spongy structure. Because the cross-section seems to be a spongy skeleton, the" moniker" PSi is utilized [3]. Usually, it is traditionally prepared by Anodize silicone substrates (Anodize method) Depending on the design parameters (current density, 
electrolyte concentration, etching Time, and substrate type), silicon crystals are produced in this manner can give varied diameters of units ranging from nanometers to tens of micrometers. PSi has a property, namely the ability to adjust porosity, which makes it appropriate for a wide range of gas sensor applications [4]. So it can be used for wide application areas including Light-emitting diode, dielectric waveguides, chemical, and biological sensors, solar cell (antireflection coating), field emission device, and photo-detector [5] Furthermore, PSi is a frequently utilized and intriguing material for its nanostructures [6]. It features a large surface area with a customizable shape and strong light interaction. This results in a fantastic PS platform for the construction of gas sensors, biosensors, and optical devices [7, 8].

There is a rising interest in creating efficient and cost-effective gas sensors for monitoring gas leaks into the atmosphere [9]. The fascination in this material stems mostly from its extraordinarily high surface-to-volume ratio, simplicity of creation, and compatibility with contemporary silicon microelectronics production procedures. $[10,11]$. In this study is to a gas sensor for ethanol and methanol was conducted on n-type silicon chips using a photo electrochemical etching method under the change of the drill current density, and the sensitivity of the PSi sensor was based on the surface nanowire structure and the size of the nanopore.

\section{Experimental Procedure}

An n-type (100) oriented silicon wafer with thickness $580 \pm 0.25 \mu \mathrm{m}$ and resistivity of $1.5-4 \Omega$.cm was used to make the Psi layer. For the porous of preparing the needed etching solution at a concentration of $40 \% \mathrm{HF}$ as well as electrochemical cell made of Teflon, $48 \%$ as hydrofluoric acid, Scharlau, Spain, has been diluted and utilized with ethanol of high purity (99.9\%). In addition, the silicon wafers were cut into small pieces approximately 2.5 $\mathrm{cm} \times 2.5 \mathrm{~cm}$ in size, after that ultrasonically cleaned for $5 \mathrm{~min}$ in ethanol for removing any contamination on the surface. Furthermore, the photo-electrochemical etching (PECE) approach is used for creating a homogeneous PS layer on the front surface related to the n-Si wafer.

PECE consists of a halogen lamp, power supply for the current source, two electrodes, and an ammeter for measuring current, also a gold grid serving as the cathode as well as a Si wafer serving as the anode. Also, such samples have been etched into electrolytes consisting of HF: Ethanol solution with various current densities $\mathrm{J}=12,24$, and $30 \mathrm{~mA} / \mathrm{cm}^{2}$ the schematic diagram related to the PECE setup is shown in Figure (1). (AFM, SPM AA3000. Angstrom Advanced Inc., USA AFM contact mode); AFM instrument was achieved in the department of Chemical Science- Baghdad University) has been used to examine the PSi surface roughness and pore diameter with nano range, also an XRD spectrometer (XRD, Shimadzu) is utilized for collecting the XRD patterns regarding bulk-silicon as well as PSi surface layers. (SEM, Inspect s50 FEI company made Holland, test was conducted in the Applied Science Department /University of Technology/ Iraq.) Will be used to investigate the properties of PS morphology The Experimental section must precede the Results and discussion. A concise and accurate description of methods enabling their reproduction by others is necessary. Sections can be divided into subsections in a sensible way so that the text would not be fragmented into many small paragraphs having a few lines. Experimental part should be Times New Roman, justified, regular; font size: 11 single. If you have any figures or tables in this section, please use the same format that will be mentioned in the "Results and discussion" part. If you have equations, please use the format and manner mentioned in the "Theoretical Part" above. 


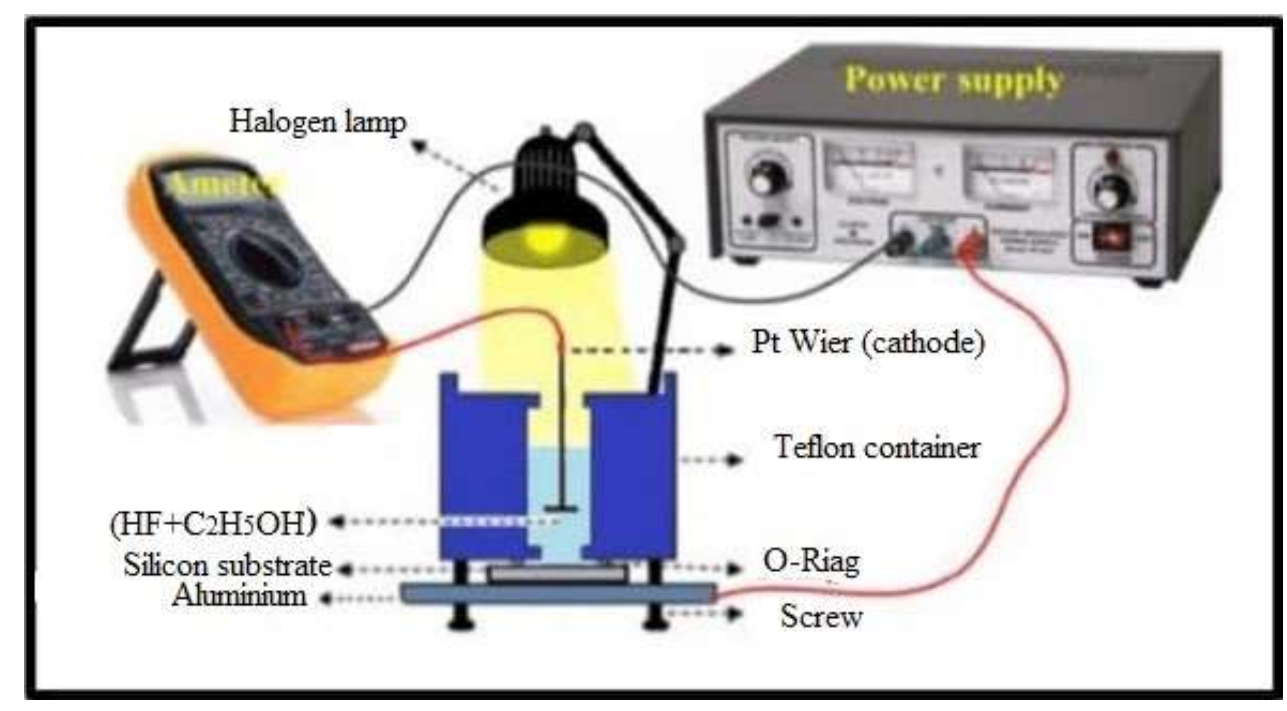

Figure 1: A schematic diagram of PECE set up [12].

Figure (2) shows a homemade gas sensor, and the measurements were carried out in a 2.5-liter glass desiccator chamber. A heater heated the substrate, and its temperature was adjusted by a variable transformer (variac) linked across a heater. The resistance change was measured using the Mable application, which was linked to a precision millimetre (Keithley 616) through a personal computer [13]. During the experiment, a rotary bump uses to refresh the chamber. All sensor measurements and the process of etching have been conducted at a room temperature.

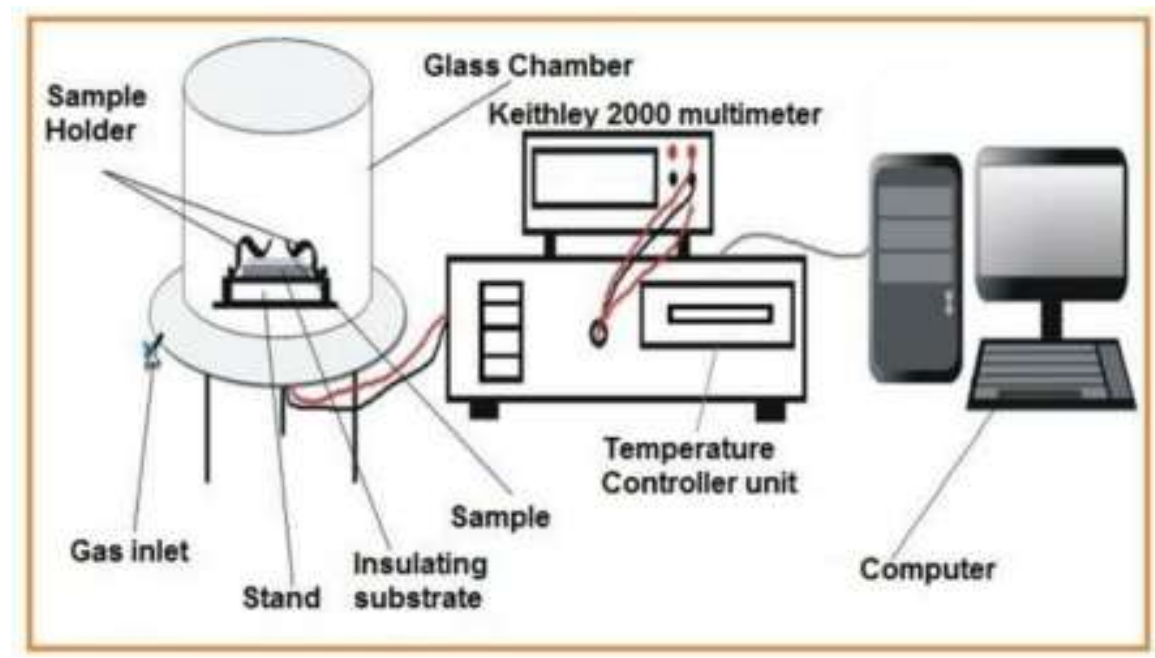

Figure 2: Experimental set-up of gas sensor [13].

\section{Results and Discussion}

Figure (3) shows the XRD pattern of c-Si and PSi samples at etching current densities about 12 and $30 \mathrm{~mA} / \mathrm{cm}^{2}$ respectively with an etching time of $10 \mathrm{~min}$. It was demonstrated that the Si layers still crystallized at orientation (100) for all PSi samples. In addition, the layers of PSi remain crystalline in-plane (100) with diffraction angles of roughly $(2 \Theta)=69.2^{\circ}, 69.15^{\circ}$, and $69.461^{\circ}$ for bulk-Silicon, PSi at $\mathrm{J}=12, \mathrm{~J}=30 \mathrm{~mA} / \mathrm{cm}^{2}$ correspondingly, and the PSi layer remains crystalline, yet is shifted slightly to small diffraction angle. These findings are due to the strain effect, which produces a little increase in the lattice parameter and, as a result, shifts the PSi peak to a small diffraction angle [14]. As the crystal size is decreased to the nanometric scale, the diffraction peak broadens, and width or FWHM of the peak is directly proportional to the size of the nanocrystalline domain [15]. 

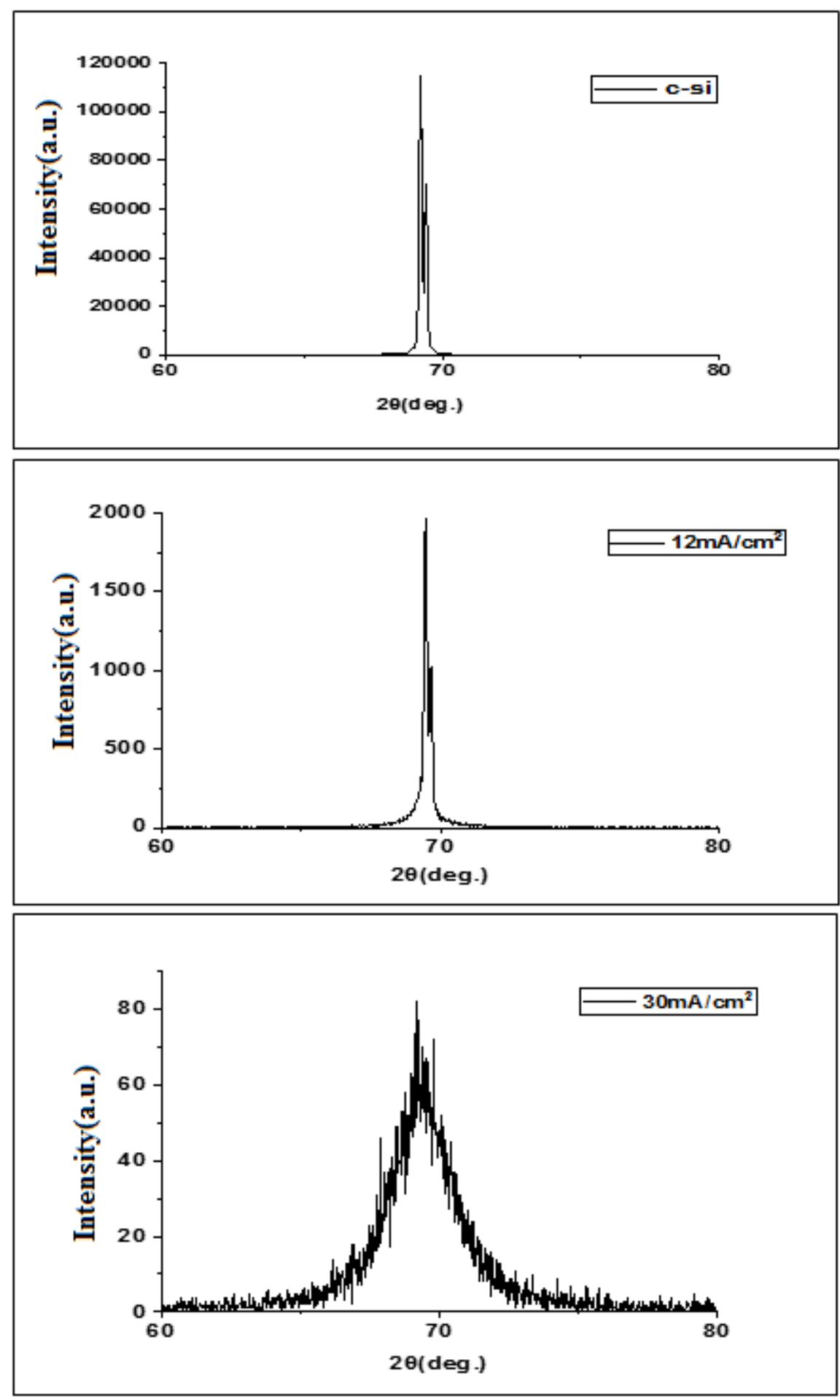

Figure 3: Illustrates the XRD diffraction patterns of the a) PSi and bulk silicon at various etching current densities of b) 12 c) $30 \mathrm{~mA} / \mathrm{cm}^{2}$, HFC of $40 \%$, and etching time $10 \mathrm{~min}$.

The AFM results were presented in Figure (4), with a Nano-metric scale. There were shown the two dimensions structure image of the PSi layer. From these images, the PSi structure can be observed by randomly distributes crystal silicon with different pore diameters on the entire surface depending on etching current density. As a result, etching time and current density may be employed to alter the size and form of the final pore structures. $[16,17]$. The average pore diameter was mention in Table 1 for PSi at $J=12$ and $30 \mathrm{~mA} / \mathrm{cm}^{2}$.and there is shows that the pore diameter and roughness of the surface increase with the increasing of etching current densities 

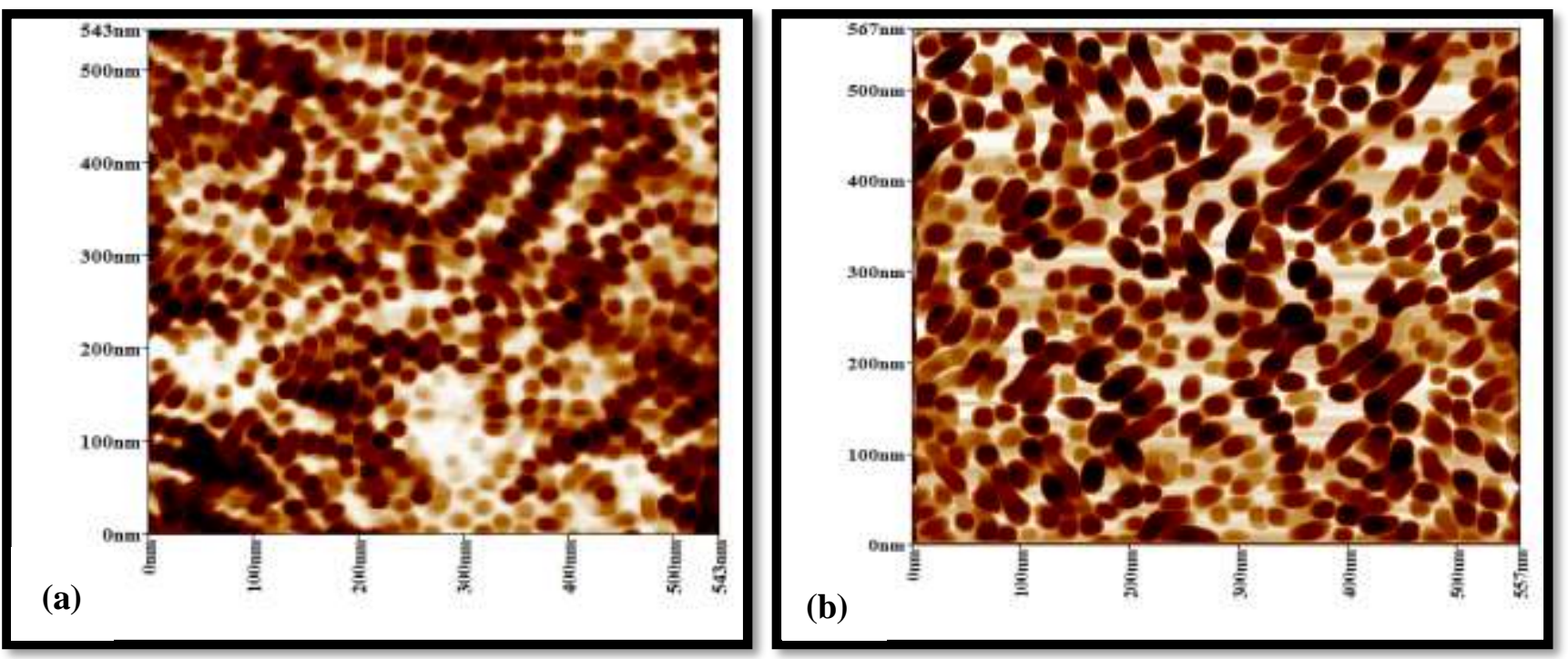

Figure 4: 2-D AFM images related to the samples of PSi at various etching current densities (a) 12 and (b) 30 $\mathrm{mA} / \mathrm{cm}^{2}, \mathrm{HFc} 40 \%$, and etching time $10 \mathrm{~min}$.

Table 1: Summary results of AFM, average diameter, and roughness at different etching current densities.

\begin{tabular}{|c|c|c|}
\hline $\mathrm{J}\left(\mathrm{mA} / \mathrm{cm}^{2}\right)$ & Ave. Diameter $(\mathrm{nm})$ & Ave.Roughness $(\mathrm{nm})$ \\
\hline 12 & 23.05 & 2.44 \\
\hline 30 & 26.23 & 8.63 \\
\hline
\end{tabular}

The SEM test was used to analyze the surface morphology of PSi samples. Figure ( $5 \mathrm{a}$, and $\mathrm{b})$ shows the SEM image of the PSi surface at etching current densities $\mathrm{J}=12$, and $30 \mathrm{~mA} / \mathrm{cm}^{2}$ respectively. It indicates the regular pore, the small pores begin to form on the Si-layer during low current density at $(\mathrm{J}=12) \mathrm{mA} / \mathrm{cm}^{2}$ figure $(5 \mathrm{a})$, while with etching current density increasing the pore diameter increased, the greater diameter of the pore was obtained with thinnest walls that separated neighbor pores shown in figure $(5 \mathrm{~b})$ this attributed to effective dissolution of Silicon at the wall of pores that lead to increasing of pore size, and consequently minimized the distance of inter-pore "wall thickness". This is due to the rapid dissolution on the silicon surface by HF solution which attacked directly followed via oxidations [18]. 

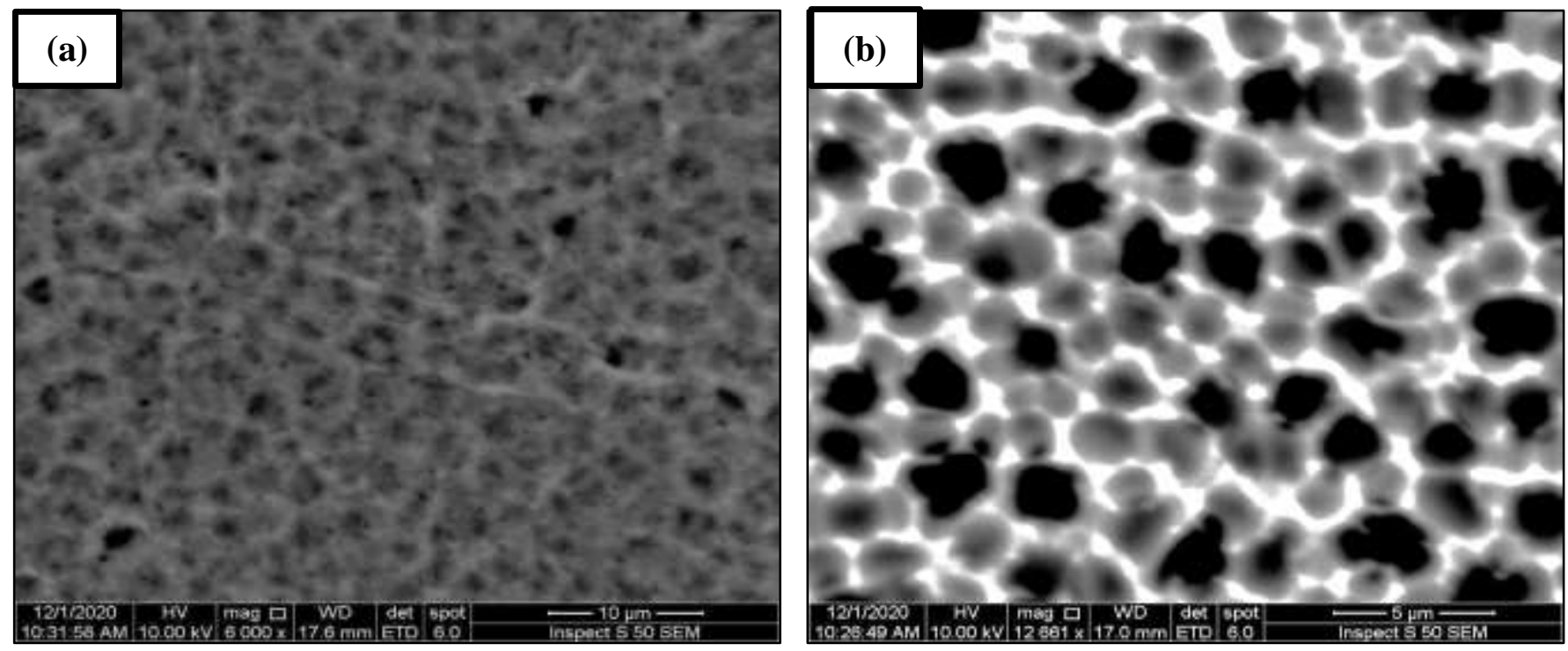

Figure 5: SEM image of PSi samples at different etching current densities (a) 12 and (b) $30 \mathrm{~mA} / \mathrm{cm}^{2}$, etching time $10 \mathrm{~min}$, and $\mathrm{HFc} 40 \%$.

The sensing characteristics of porous silicon samples for the ethanol and methanol gas were shown in Figure 6. Sensor sensitivity $(\mathrm{Sg})$ is defined as $\mathrm{Ra} / \mathrm{Rg}$ [13], where $\mathrm{Ra}$ is the sensor's electrical resistance in air and $\mathrm{Rg}$ is its resistance in mixed gas and air. Figure $(6 a$ and $b)$ shows the sensitivity of samples that were prepared with etching current density $\mathrm{J}=12,24,30 \mathrm{~mA} / \mathrm{cm}^{2}, 40 \% \mathrm{HFc}$ etched solution and timed etching about 10 minutes in the presence of $500 \mathrm{ppm}$ methanol and ethanol, respectively. The sensitivity was determined by calculating the sample's resistance with a constant voltage. As it turns out, when the sample is exposed to ethanol or methanol, the sensitivity improves. The best sensitivity to ethanol was about (1.809) at current density $\mathrm{J}=30 \mathrm{~mA} / \mathrm{cm}^{2}$, while the best sensitivity of methanol was about $(0.3808)$ at $\mathrm{J}=12 \mathrm{~mA} / \mathrm{cm}^{2}$. The long reaction time is due to the large surface area and the presence of nanopores, which take long periods to achieve the equilibrium adsorption state. This interpretation is consistent with the AFM results presented in Table 1, which show that the sample made with $\mathrm{J}=30 \mathrm{~mA} / \mathrm{cm}^{2}$ most observable porous structures $[19,20]$.

Greater porosity means a larger surface area, and thus a larger reactive surface for the gas sensor ethanol. It was illustrated in Fig. 6 the gas sensitivity increases after injection of ethanol gas into the reaction chamber and reaches the saturation level, then decreases when the sample is exposed to air. The gas response was found to be $\mathrm{Ra} / \mathrm{Rg}=1.809,1.4209$, and 1.3132 at an etching current density of $\mathrm{J}=12,24$, and $30 \mathrm{~mA} / \mathrm{cm}^{2}$, where $\mathrm{Rg}$ is the resistance when the sample is exposed to ethanol. The higher response was at $\mathrm{J}=30$ compared with other samples at 12 and $24 \mathrm{~mA} / \mathrm{cm}^{2}$. The higher sensitivity of the porous silicon film prepared with PECE technology may be attributed to the optimal number of uniform pores on the surface, larger surface area, greater surface roughness, and the greater ethanol oxidation rate, this results obeyed with SEM and AFM results. The effect of changing the etching current densities in making porous silicon was clear on the pore diameter and surface roughness, and this is consistent with the results of the AFM examination, where the pore roughness was equal to $(2.44 \mathrm{~nm})$ and the pore diameter was equal to $(23.05 \mathrm{~nm})$ at $\mathrm{J}=12 \mathrm{~mA} / \mathrm{cm}^{2}$, while at $\mathrm{J}=30 \mathrm{~mA} / \mathrm{cm}^{2}$ The surface roughness is $(8.63$ $\mathrm{nm})$ and the pore diameter is $(26.23 \mathrm{~nm})$. This is also consistent with the results of the SEM examination, where the higher the etching current density, the greater the pore diameter, the higher the surface roughness and the smaller the pore wall, and this leads to an increase in the surface area exposed to the gas and an increase in the energy gap on the surface [6,7]. The lowest ethanol gas response was also obtained for $\mathrm{Ra} / \mathrm{Rg}=1.313257$ at etching current density of $12 \mathrm{~mA} / \mathrm{cm}^{2}$.but at ethanol gas the higher sensitivity was (0.380801) at etching current density $\mathrm{J}=12 \mathrm{~mA} / \mathrm{cm}^{2}$ then at $\mathrm{J}=\left(24 \mathrm{~mA} / \mathrm{cm}^{2}\right)$ about $\mathrm{Ra} / \mathrm{Rg}=(0.161195093)$ and the lowest was at $\mathrm{J}=30 \mathrm{~mA} / \mathrm{cm}^{2}$ with $\mathrm{Ra} / \mathrm{Rg}=(0.12389692)$. 

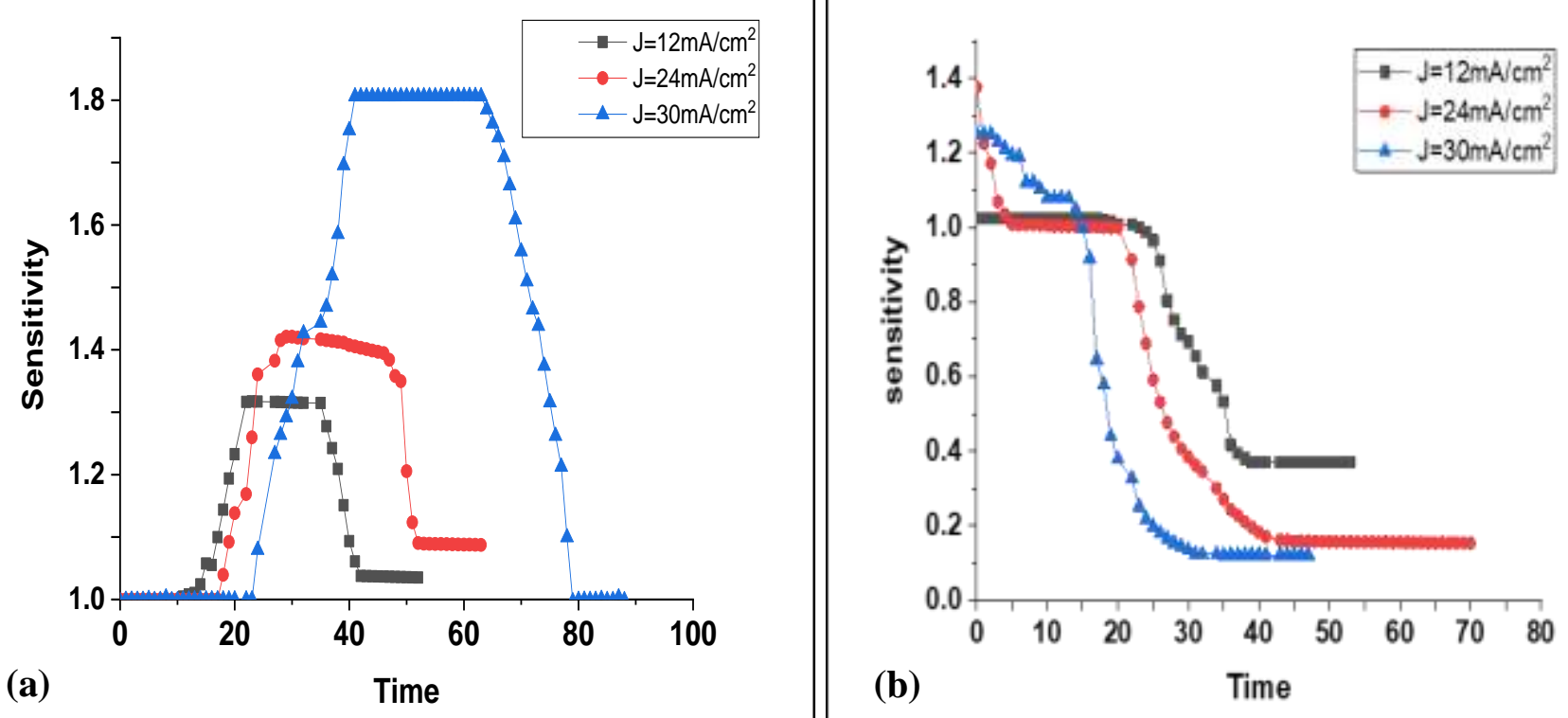

Figure 6: Typical gas sensor responses ( $\mathrm{Ra} / \mathrm{Rg}$ ) to a PS with different etching current densities) 12, 24, 30 $\mathrm{mA} / \mathrm{cm}^{2}$ sensor for (a)ethanol and (b)methanol gases at an operating temperature of $60^{\circ} \mathrm{C}$.

Figure (7) illustrates the variation in response time as a function of the sensitivity of different etching current densities. Response time represents the time it takes for the sample to interact with the gas, and the recovery time represents the time it takes for the sample to return to its normal state, ie the state of the sample before pumping the gas. Obviously, the response time increases with time and has a higher value of $31 \mathrm{~s}$ at a current density of 30 $\mathrm{mA} / \mathrm{cm}^{2}$ and then decreases again. The large response time and recovery times may be due to the high gas absorption rate and gas absorption agreement [21]. The variation in response and recovery time for the two gases used is because the melting and boiling temperatures of ethanol are relatively higher than that of ethane. After all, ethanol can form strong bonds such as hydrogen bonds. Among the molecules that ethane cannot do. Table (2) shown the recovery and response times for the PSi samples.

Table 2: displays the modified samples' recovery and response times.

\begin{tabular}{|c|c|c|c|c|c|c|}
\hline $\mathrm{J}(\mathrm{mA} / \mathrm{cm} 2)$ & GAS & $\mathrm{Ra}(\mathrm{KOHM})$ & $\mathrm{Rg}(\mathrm{KOHM})$ & Sensitivity & $\begin{array}{c}\text { RESPONSE } \\
\text { TIME(sec) }\end{array}$ & $\begin{array}{c}\text { RECOVER } \\
\text { TIME(sec })\end{array}$ \\
\hline 12 & ethanol & 4.23 & 3.211 & 1.3132 & 10 & 23 \\
\hline 24 & & 7.266 & 5.1135 & 1.4209 & 17 & 29 \\
\hline 30 & & 1.2446 & 0.688 & 1.8090 & 23 & 45 \\
\hline 12 & methanol & 212.856 & 558.969 & 0.380801082 & 23 & 35 \\
\hline 24 & & 32.87316 & 203.934 & 0.161195093 & 20 & 41 \\
\hline 30 & & 16.0392 & 129.456 & 0.123896923 & 16 & 31 \\
\hline
\end{tabular}



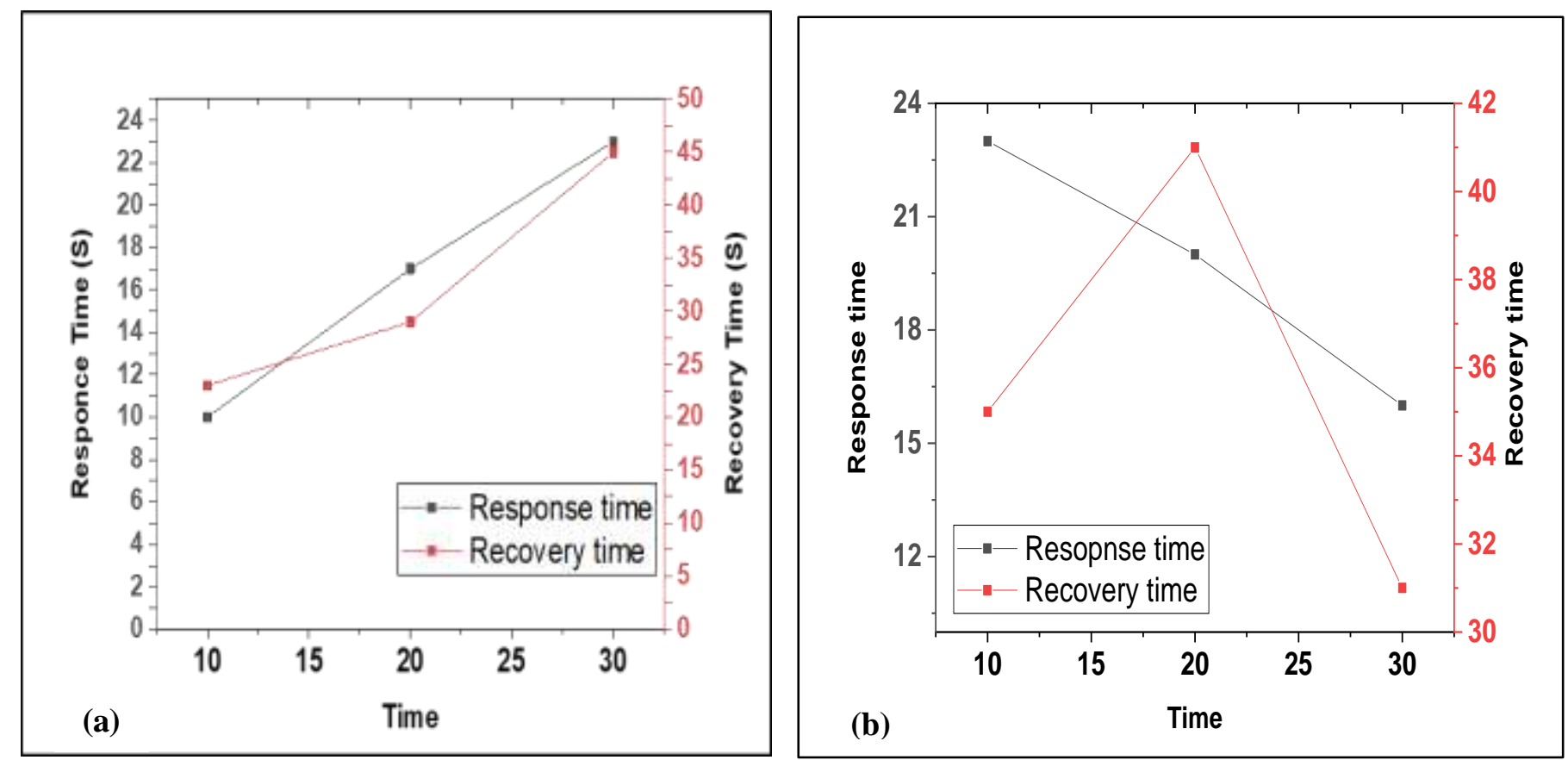

Figure 7: Response and recovery time versus start time for (a) ethanol (b) methanol

\section{Conclusions}

The Conclusions section contains a brief analysis of principal findings and significance of the work. The Conclusions must not be a re-worded abstract. Unlike an abstract, the Conclusions are primarily determined to those who read the whole paper. Conclusions should be Times New Roman, justified, regular; font size: 11 single. In summary, the sequential preparation method with different etching current densities was successfully used as a gas sensor. The results obtained indicated that the structural properties of the PSi layer depend on the etching time, surface roughness, layer thickness, etching current density, and pore diameter. The SEM examination indicates that the pore diameter of the PS layer increases with increasing etching current density, with the pores appearing sponge-like. Gas sensitivity to ethanol for all samples PSi increases with changing samples, this means that the best performance of the sensor is when the sensor is operating at room temperature and thus ensures the adequate life span of the sensor and does not require more electrical energy for the process. This makes the sensor economical and ideal. It was observed that the highest response was at the current density of $30 \mathrm{~mA} / \mathrm{cm}^{2}$, the optimum sensitivity of the PSi-based gas sensor is 1.8090 at an ethanol concentration of 500 $\mathrm{ppm}$ at room temperature. The impressive result also shows response time ( 23 seconds), recovery time (45 seconds).

Acknowledgment: We would like to thank the University of Technology and the Applied Science Department in Baghdad, Iraq, for their assistance in conducting this study.

Conflict of Interest: The authors declare that they have no conflict of interest.

\section{References}

[1] R. Jarimavičiute-Žvalioniene, J. Waluk, and I. Prosyčevas, "Photoluminescence properties of porous silicon with CdSe/ZnS quantum dots," Medziagotyra, vol. 17, no. 3, p. 232-235, 2011.

[2] C. Vinegoni, M. Cazzanelli, and L. Pavesi, "Porous silicon microcavities," Silicon-Based Material and Devices, p. 123-192, 2001.

[3] M. M. Hassan and M. A. Fakhri, "2-D of Nano Photonic Silicon Fabrication for Sensing Application," Digest Journal of Nanomaterials and Biostructures, vol. 14, no. 4, p. 873-878, 2019.

[4] E. Galeazzo, H. E. M. Peres, G. Santos, N. Peixoto, and F. J. Ramirez-Fernandez, "Gas sensitive porous silicon devices: Responses to organic vapors," Sensors and Actuators B: Chemical, vol. 93, no. 1-3, p. 384390, 2003. 
[5] J. Charrier, E. Le Gorju, L. Haji, and M. Guendouz, "Optical waveguides fabricated from oxidised porous silicon," Journal of Porous Materials, vol. 7, no. 1-3, p. 243-246, 2000.

[6] U. M. Nayef, H. T. Hussein, and A. M. Abdul Hussien, "Study of photoluminescence quenching in porous silicon layers that using for chemical solvents vapor sensor," Optik, vol. 172, no. July, p. 1134-1139, 2018.

[7] H. T. Hussein, U. M. Nayef, and A. M. A. Hussien, "Synthesis of graphene on porous silicon for vapor organic sensor by using photoluminescence," Optik, vol. 180, p. 61-70, 2019.

[8] N. Hussein, M. M. Khadum, "Evaluation of the Biosynthesized Silver Nanoparticles" Effects on Biofilm Formation," Journal of Applied Sciences and Nanotechnology, Vol. 1, P. 23-31, 2021.

[9] V. Aroutiounian, "Metal oxide hydrogen, oxygen, and carbon monoxide sensors for hydrogen setups and cells," International Journal of Hydrogen Energy, vol. 32, no. 9, p. 1145-1158, 2007.

[10] L. Boon-Brett, J.Bousek, G.Black, P.Moretto, et al., "Identifying performance gaps in hydrogen safety sensor technology for automotive and stationary applications," International Journal of Hydrogen Energy, vol. 35, no. 1, pp. 373-384, 2010.

[11] A. Z. Adamyan, Z. N. Adamyan, V. M. Aroutiounian, A. H. Arakelyan, , et al., "Sol-gel derived thin-film semiconductor hydrogen gas sensor," International Journal of Hydrogen Energy, vol. 32, no. 16, p. 41014108, 2007.

[12] I. M. Ali, M. A. Kaood, "Improving NO2 Sensitivity of Porous Silicon by functionalization surface with copper as catalyst," Science International Lahore, vol. 29(6), p.1237-1240, 2017.

[13] P. T. Patil, R. S. Anwane, and S. B. Kondawar, "Development of Electrospun Polyaniline/ZnO Composite Nanofibers for LPG Sensing," Procedia Materials Science, vol. 10, p. 195-204, 2015.

[14] R. G. Kadhim, R. A. Ismail, and W. M. Abdulridha, "Structural and Optical Properties of Porous Silicon Prepared by Electrochemical Etching," Journal of the Korean Ceramic Society, vol. 39, no. 2, pp. 109-112, 2002.

[15] O. Bisi, S. Ossicini, and L. Pavesi, "Porous silicon: A quantum sponge structure for silicon based optoelectronics," Surface Science Reports, vol. 38, no. 1, p. 1-126, 2000.

[16] V. S. Vendamani, Dang, Z.Y, Ramana, P., Pathak, A.P., et al., "Fabrication of porous silicon based tunable distributed Bragg reflectors by anodic etching of irradiated silicon," Nuclear Instruments and Methods in Physics Research Section B: Beam Interactions with Materials and Atoms, vol. 358, p. 105-111, 2015.

[17] M. K. Abood, M. H. A. Wahid, E. T. Salim, and J. A. Saimon, "Niobium Pentoxide thin films employ simple colloidal suspension at low preparation temperature," International Conference on Applied Photonics and Electronics, vol. 162, 2017.

[18] A. A. Sulaiman, "Effect of $\gamma$ - Irradiation on the n- Porous Silicon Structures Prepared by Electrochemical Etching," Rafidain Journal of Science, vol. 27, no. 2, pp. 173-180, 2018.

[19] Y. F. Zhao, Yu-Ping Sun, Xiu Yin, Guang-Chao Yin, et al., "Effect of Surfactants on the Microstructures of Hierarchical $\mathrm{SnO}_{2}$ Blooming Nanoflowers and their Gas-Sensing Properties," Nanoscale Research Letters, vol. 13, 2018.

[20] R. Jabbar, N. N. Hussein, "Evaluation The Antibacterial Activity of Biosynthesis Silver Nanoparticles by Lactobacillus Gasseri Bacteria," Journal of Applied Sciences and Nanotechnology, Vol.1, no 3, P. 8695,2021.

[21] A. M. Alwan, A. B. Dheyab, and A. A. Jabbar,"Study of the Influence of Incorporation of Gold Nanoparticles on the Modified Porous Silicon Sensor for Petroleum Gas Detection," Engineering and Technology Journal, vol. 35, no. 8, p. 811-815, 2017. 